Témoigner Témoigner. Entre histoire et mémoire

Getuigen Revue pluridisciplinaire de la Fondation Auschwitz

$124 \mid 2017$

La musique dans les camps

\title{
Herdenkingsplekken in Brussel en Vlaanderen: erkenning, bewaring en onderhoud
}

\section{Daniel Weyssow}

Traducteur : Gorik de Henau

\section{(2) OpenEdition \\ Journals}

\section{Édition électronique}

URL : https://journals.openedition.org/temoigner/5837

DOI : $10.4000 /$ temoigner.5837

ISSN : 2506-6390

Éditeur :

Éditions du Centre d'études et de documentation Mémoire d'Auschwitz, Éditions Kimé

Édition imprimée

Date de publication : 2 avril 2017

Pagination : 160-165

ISBN : 978-2-930953-00-7

ISSN : 2031-4183

Référence électronique

Daniel Weyssow, «Herdenkingsplekken in Brussel en Vlaanderen: erkenning, bewaring en onderhoud», Témoigner. Entre histoire et mémoire [Online], 124 | 2017, Online op 30 novembre 2021, geraadpleegd op 01 décembre 2021. URL: http://journals.openedition.org/temoigner/5837 ; DOI: https://doi.org/

10.4000/temoigner.5837 


\section{Memorial site}

\section{HERDENKINGSPLEKKEN IN BRUSSEL EN VLAANDEREN: ERKENNING, BEWARING EN ONDERHOUD}

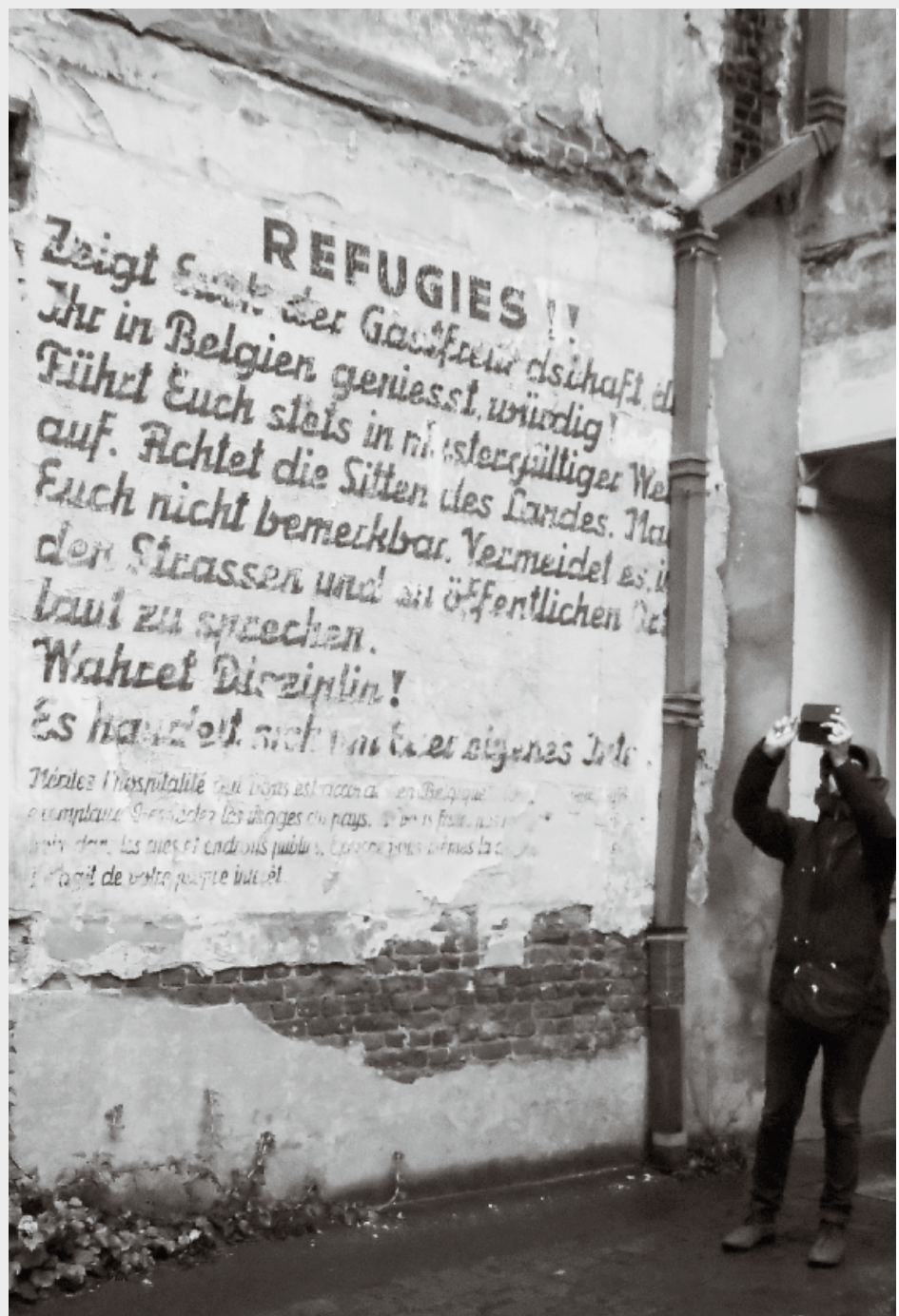
els) worden Stolpersteine (gedenktebij de laatste woningen van personen werden opazals door de bezette sporen die de feiten het best weerspiegelen en waarmee de overdracht kan worden verzekerd - zij die in direct verband staan met de geschiedenis kunnen mettertijd eventueel worden opgenomen op een erfgoedlijst of zelfs worden beschermd door Monumenten en Landschappen. Maar het spreekt vanzelf dat daarvoor eerst de herint vello hering getelheid, de erosie van het geheugen, bijkt het grootste gevar dat moet warden bezworen. Man als de horde de plekken, sporen encturenisen in de open, sporen en getuigenissen

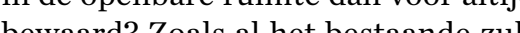

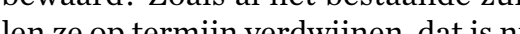
len ze op ternijn werd be bewaren moten we wak bewaren, moeten we waakzaam blijven stadsenting stadsontwikkelingsprojecten. On het en, specialisten en verenigingen het gen, specialiks en

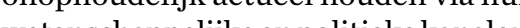
We gan bese We gan besefen hoe fragiel de gedachtenis in de openbare ruimte beelden in onze directe ongeving beelden in onze diste ongeving. Het ortvan Bret gebouw me Ten belangrijke gedachtephet phetgotepublikenscholieren, Zodat de mishandelingen die tijdens de mishandelingen die er tijdens de

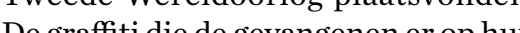
Delmuren tekenden, dreigen er op hu verdwijnen, ondanks pogingech eron alontenwoordige vocht in het fort terug te dingen. Gelukig werden die getuigenissen onnidellik na de oorlog geinventaris De Dossinkazer

De Dossink darerne, een Ss-door- voor de deportatie van de Belgische Joden, werd omgebouwd tot een appartementencomplex (Mesnard 2013). Wat de bewuste cruciale periode betreft, is het authentieke karakter van de plek dus aangetast. Ze kan niet door het publiek worden bezocht, met uitzondering van een gedenkteken in het souterrain van het toegangsportiek Het museum Kazerne Dossin, dat er logischerwijs had moeten worden ondergebracht, vond uiteindelijk een plek aan de overzijde. Aan alle pedagovorwarden werd optimaal voldaan, dat is het probleem niet. Maar de oorspronkelijke plek waar het museum had kunnen staan, kan als gedachtenisspoor alleen nog worden bekeken vanaf de vierde verdieping van het nieuwe gebouw.

Op nummers 25 en 27 van de Rogier Van der Weydenstraat, niet ver van het Zuidstation, bevond zich net voor de oorloghet Comité d'Assistance aux Réfugiés juifs (Bijstandsraad voor Joodse Vluchtelingen). ${ }^{1}$ Op een muur van het binnenhof staat nog altijd een geschilderde tekst in het Duits en het Frans met aanwijzingen hoe vluchtelingen zich het best konden gedragen om discreet in de wijkbevolking op te gaan. Die muuropschriften werden onlangs beschermd. Hoewel ze sinds de jaren dertig nauwelijks schade opliepen, is het er de laatste maanden slecht mee gesteld. Het plaaster brokkelt af en daarmee verdwijnen ook de geschriften. Heeft de eigenaar contact opgenomen met Monumenten en Landschappen? Hoe kan deze plek in stand worden gehouden? Als we willen dat dit toch wel bijzondere getuigenis blijft bestaan, zal er dringend een antwoord moeten komen op deze vragen. Gestapo-hoofdzetel, op nulders van de 


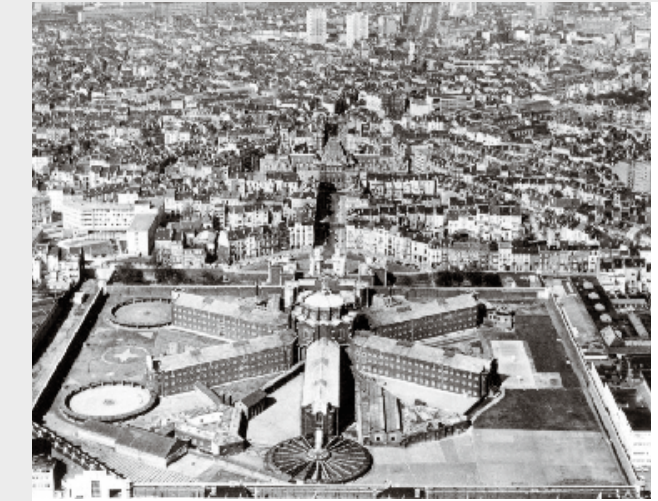

$\uparrow$ De gevangenis van Sint-Gillis in vogelperspectief

$\diamond$ De gevangenis van Sint-Gillis vandaag

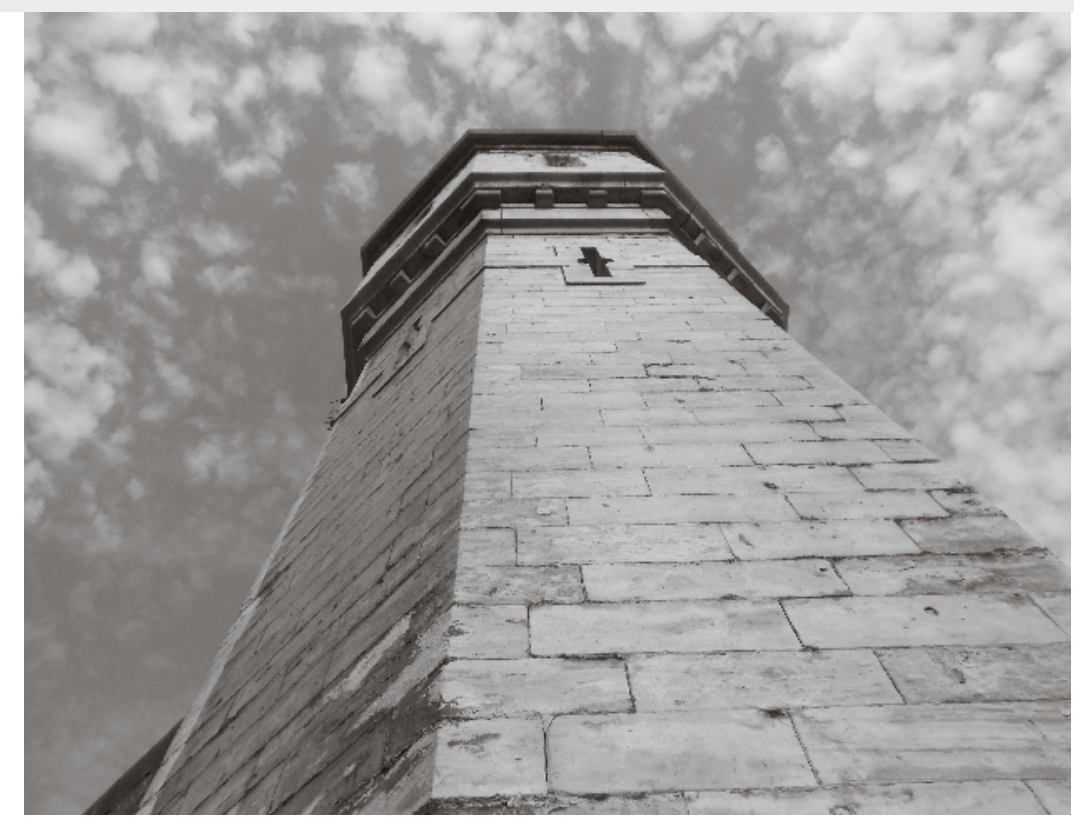

.• en 453 van de Louizalaan, waren ook bijna vergeten (Weyssow 2013). Als de historicus en cineast André Dartevelle in 1995 de twee gebouwen (en het oog op een documentaire, du het oog op een docunentaire, dan zou er vandaag nienand nog over hebben gesproken. Zeldzame getuigenissen, in of op de Znur gekrast of getekend door de Joodse slachtoffers en de verzetsstrijders die er waren opgesloten, ontsnapten als bij wonder aan de onversching ineid van de elgenaars en de geplande geruisloze verdwijning. Ze is tijd dat er ook een serieuzu, dus het is tijd dat er ook een serienze en volledige studie ann wordt gewijd. Want de bewuste plekken blijven vooralsnog het $\begin{array}{ll}\text { (2) http:// } & \text { In de gevangenis van Sint-Gillis } \\ \text { petitionspatrimoine. } & \text { Inter }\end{array}$ petitionspatrimoine. zaten tijdens de twee wereldoorlogen
blogspot.be/ (3) http://www.ms-a.be/pdf/ een groot aantal door de bezetter gear$\begin{array}{ll}\text { MSA - booklet 2014 } & \text { resteerde verzetsstrijders. Na afloop van } \\ \text { URBANISME.pdf } & \text { de Eerste Wereldoorlog werd de cel van }\end{array}$
Edith Cavell een gedenkplek. Elk jaar werd ze bezocht door een Engelse deleetie diehuld brach gatie diehuldebrachtaan Cavells moed, maar door de recente renovatie van de eindenis lijht er aan die tradtie een een veras een voorsmaakje van wat achter de chatste beichten wordt bele gevanlatste berichten wordt de hele gevandat in 2017 zoup bedreigd, een project ceu 政 sen duizenct ${ }^{3}$ te bes. bescherming in, maar de plek zou niet van werk likt wel hel Dezer van werken lijkt wel heel sterk op de onvorming van de Dossinkazerne. Uit angripende getuigenissen van slachtvan (zipo-Sd(Gests verzetsstrijders) het hize (GT) blist nochtans dat holitier een sleutelplek betrof van het veldpolize-S(GFP) blijkt no Geheime len er trouwens nogmaals op wijzen dat er in Brussel geen 'historische' of 'herinneringsplek' is die werd omgevorm tot documentatiecentrum of museum, met uitzondering dan van het NatioVan an Lint 14 in Andeclect, war ledenvan het$$
\text { Dekazer }
$$

van de Nationale Schietbean en inbrip van het reveld terrein, me berden, werdenin 1962 ande Nation, Institurt 2 vech ational o (NIN), waana ze plats ba Geien het nog seeds bestande kerkGerien het no herbon de jichting het teonderhouden. Maar blik zijn de telis en op dit ogenReyersan, net als de gevangenis van Sint-Gillis, net als de gevangenis van Sint-Gilli, gedorij on op georgani-

moet op die plek een 'mediastad' oprij${ }^{5} \mathrm{Het}$ ereveld van de gefusilleerden lijkt volgens de beschikbare plannen oorlopig niet bedreigd, maar we kunnen maar beter waakzaam blijven. Om et toekomstige project eenvormig te ouden, zouden de 261 grafstenen met gefusilleerden van de Tweede Wereldoorlog deel kunnen uitmaken van een compromis waarbij de stoffelijke resten cer plat. in Sint-Land gent in Sint-Lanbrects-Woluwe, (a) van terdome tot het Georges Henipar

Gedenkplaten zijn een andere, envoudger manier om degedachtenis in stand te houden aan de mannen en Wereldoorlog Ze zijn weninde Tweede je vindt ze hier en daar als je langs een woning loopt $Z_{0}$ is er al je langs een innert an de redding van de Joodse

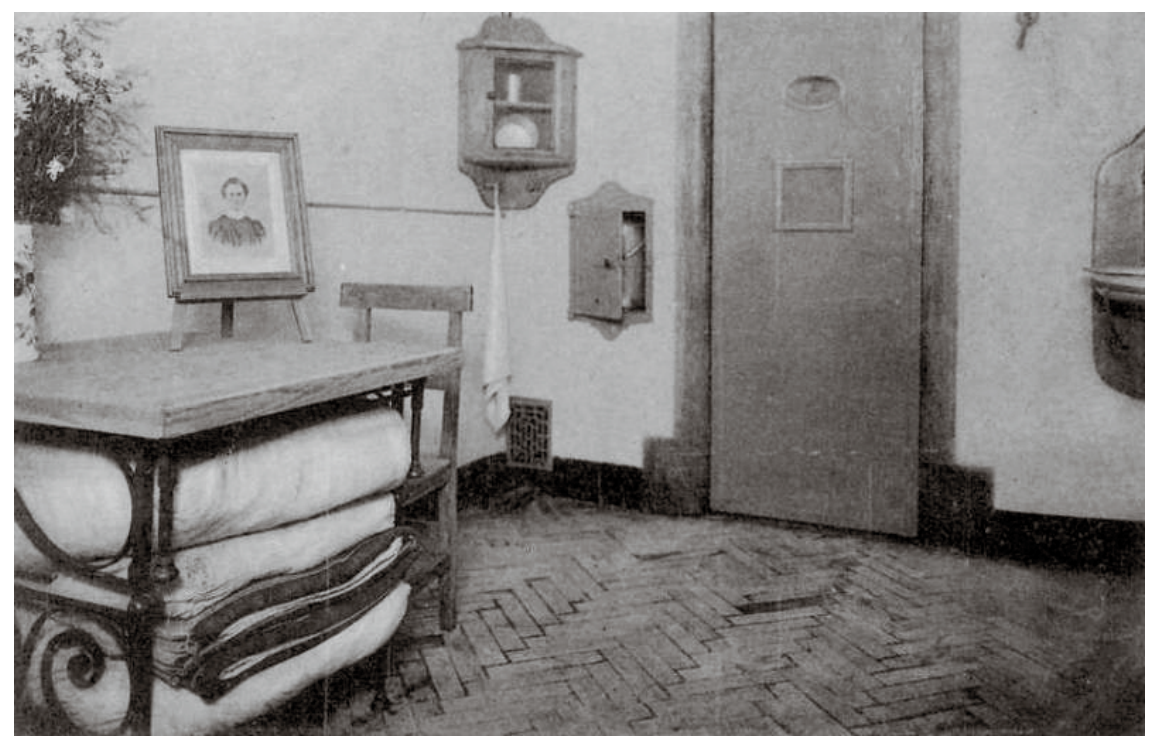

$\$$ De celvan
Edith Cavell

(4) Voor meer info over de
drukkersplat van de valse

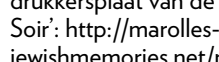
Jewishmemories.net/n/
la-plaque -photograve-du-
faux-soir/ (geraadpleegd 31 januari 2017 .

(5) http://www.

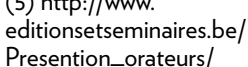

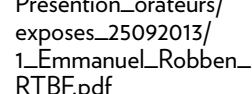




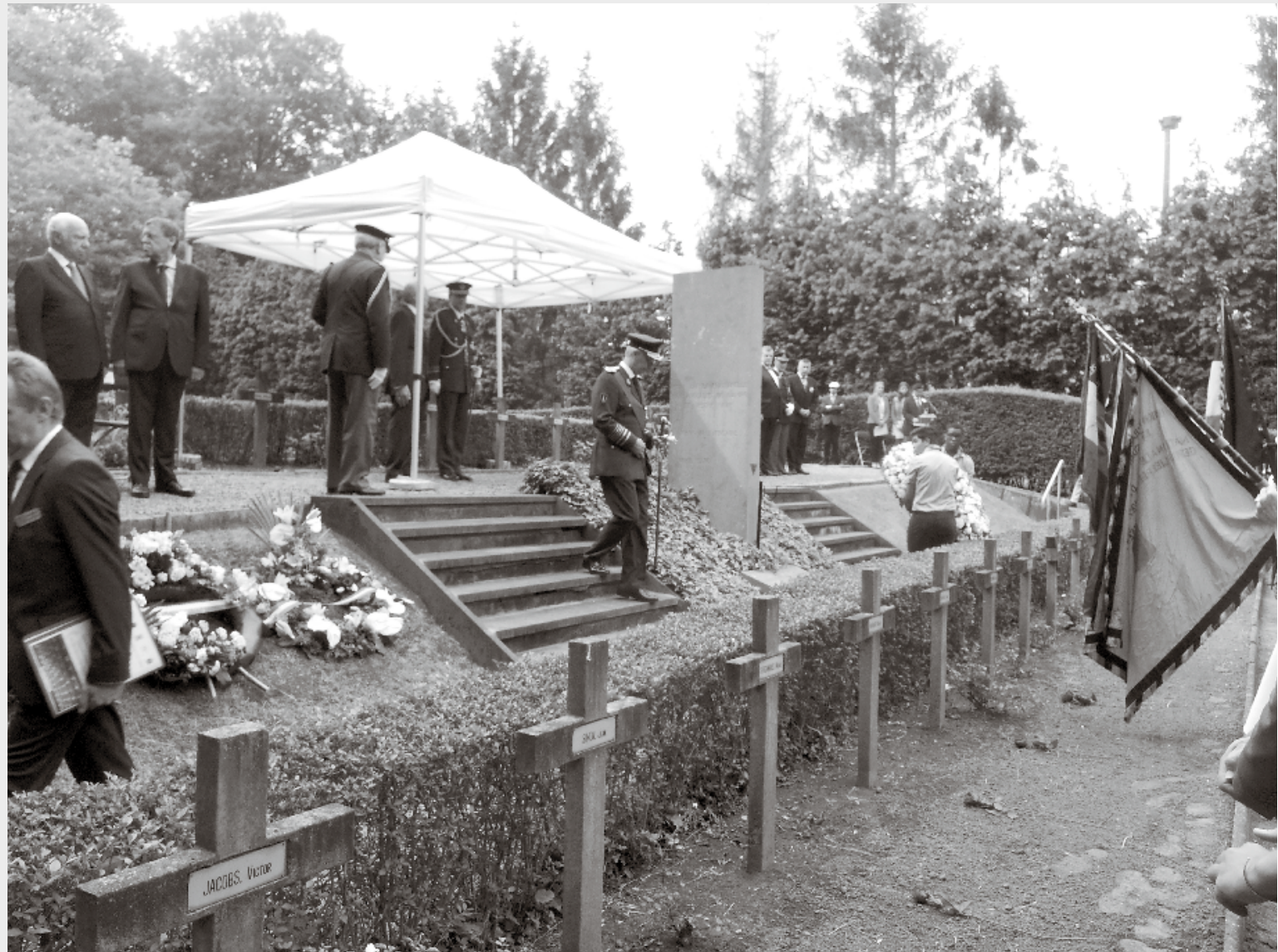

Herdenkingsplechtigheid aan plechtigheid aan
het ereveld van de gefusilleerden, 29 mei 2016

(6) Voor info over Paul klooster van de Allerheiligste Verlosser in Anderlecht: hittp:///marollesewishmemories.net/nl//
paul-halter-clemenceaw/ paul-halter-clemenceaul
(geraadpleegd 31 januari

$\bullet \bullet$ meisjes die zich schuilhielden in een kloosterpensionaat in de Clemenceauho hor verme de hoger vermelde, geduchte Geheime Feldpolizei (GFP), gelegen aan de incericht als museum mar we herberg. De eigenar wilde lieverg he de vistaling van de vervloekte dat de uitstraling van de vervloekte kunstenar Van Gogh - op die plek hij an de Academievor Schene Kanjen stu Acade - von Schone Kunwerd Hij ging er dus med akkoord da er een gedenkplaat kwam voor de op dat adres mishandelde verzetsstrijders, maar dan wel op de binnenplaats en niet op de voorgevel. Van buitenaf is ze dus niet te zien. De toekomst van de plaat hangt af van de op (dit ogenblik welwillende) eigenaar, die er helemaal alleen op toeziet. Willen ze op die plek de dig houden, dan zullen de gedachtenisverenigingen die het voorstel daartoe hadden geopperd ook moeten toezien phet behoud ervan. ten en pleinen. Het recentste werd in ingehuldigd op 6 oktober 2015 in Sintherinnering aan de slachtoffers leven-

En dan zijn er de borden op stra-
Agatha-Berchem ter nagedachtenis aan baron Paul Halter, wiens naam nu verbonden is met een plein op de kruising tussen de Mettewie- en de Machtenslaan in Molenbeek. Behalve de hierboven geschetste actie en ook en reks verzetsdaden tijdens de Tweede Wereldoorlog danken we Them de oprichting (in 1980) van de Stichting Auting (in 1980) van de Stichting Auschwitz, die hij voorzat 2013. De borden dragen bij tot het in 2013. De borden dragen bij tot het in verdientelijke figuren, whering aan de burgerzin van de voorbijgangers de burgerzin van de voorbijganger wort aangescherpt.

De Stolpersteine van de Duitse kunstenaar Günther Demnig ter. Elke tegel vermeldt nan de bezetteplats, geborte(behalve in het geval van de zeldzame (behalve in het geval van de zeldzame overent, opgepakt, al dan nist bij een razzia. Ze wo toegangsdeur van det trottoir voor de toegangan de sand hatstebekende woning van de slachtoffers. Er werden al meer dan 30000 tegels geplaatst in deel in Duitshand en Oosteni. Hoe deel in Duitsland en Oostenrijk. Hoe lang zullen ze bewaard bljven? Zolang per. pen. Dat wil zeggen dat ze maar zulle bij beshading zolang ze belangrijk bij beschadiging zolang ze belangrijk blijven voor de bevolking.

beelden tonen aan dat het oprichten en in stand houden van herdenkingsplekken slechts mogelijk is wanneer burgerinitiatieden door de overheid. Om die den door de oveneid. Om die plekken monumenten, platen en tegels te laten in , blijen het noodzakelijk de feiten

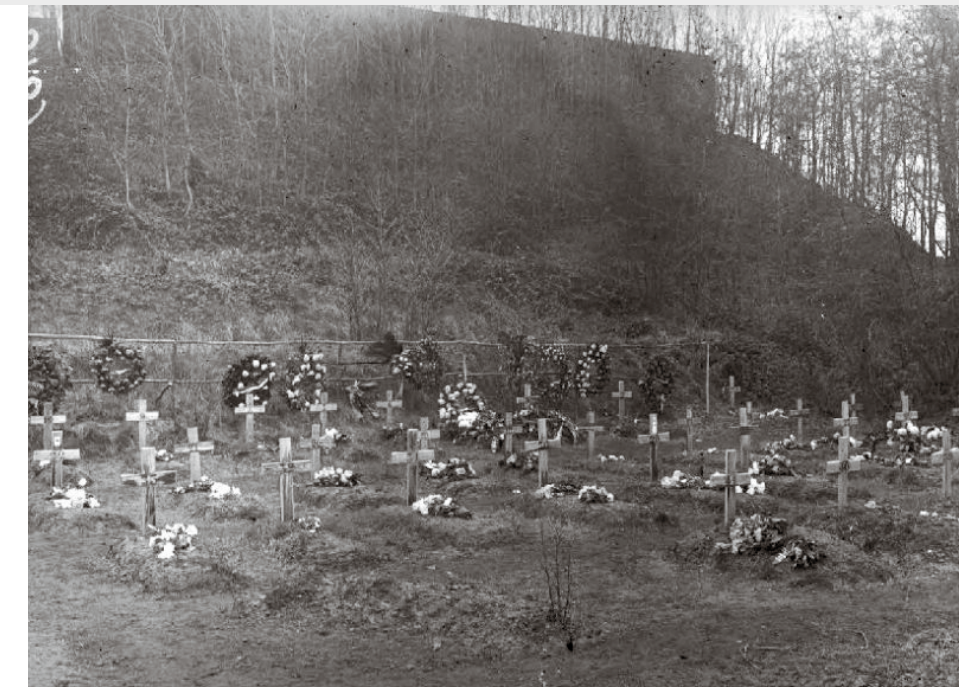

Het ereveld van

van context te voorzien. Het bijbrengen va historisch besef en burgerzin verloopt via niet-aflatende pedagogische inspanningen, eerst en vooral in de scholen. I

$$
\begin{array}{r}
\text { Daniel Weyssow } \\
\text { Vertaling uit het Frans: Gorik de Henau }
\end{array}
$$

$$
\rightarrow \text { Meer weten }
$$

$\widehat{\text { http:} / / / m a r o l l e s-j e w i s h m e m o r i e s . n e t / n l / / ~-~ C i r c u i t ~ M a r o l l e n-~}$
Zuidstation: geschiedenis en geheugen van een Brusselse wijk

$\rightarrow$ Bibliografie

$\diamond$ Philippe Mesnard, 'Caserne Dossin (Malines). Le parti pris de la clarté et des droits de l'homme', Témoigner. Entre histoire et mémoire

$\diamond$ Olivier Van der Wilt, 'Les détenus de la SIPO-SD en Belgique: des caves de lavenue Louise aux cellules de Breendonk', in Dan Weyssow (red.), Les Caves de la Gestapo. Reconnaissance
conservation. Pariis: Kimé 2013, 121-133. $\diamond$ Daniel Weyssow (red.), Les Caves de la Gestapo. Reconnaissance
et conservation, Parijis: Kimé, 2013. 